\title{
Measurement of density and wetness in snow using time-domain reflectometry
}

\author{
Martin Schneebeli, ${ }^{1}$ Cécile Coléou, ${ }^{2}$ François Touvier, ${ }^{2}$ Bernard Lesaffre ${ }^{2}$ \\ ${ }^{1}$ Swiss Federal Institute for Snow and Avalanche Research, CH-7260 Davos Dorf, Switzerland \\ ${ }^{2}$ Centre d'Études de la Neige, Centre National de Recherches Météorologiques, Météo-France, 38406 Saint-Martin-d'Hères Cedex, France
}

\begin{abstract}
Time-domain reflectometry (TDR) is widely used in soil physics to determine water content. Existing equipment and methods can be adapted to measurements of snow wetness. The main advantages compared to other methods are flexibility in constructing sensors, minimal influence on snow cover during measurements and sensors can be multiplexed. We developed sensors suitable for continuous and non-continuous measurements of snow wetness and density, measured the apparent permittivity in different snow densities and snow types, and compared the measurements to existing mixing formulas for mixtures of snow and air. In dry snow, density was measured from 110 to $470 \mathrm{~kg} \mathrm{~m}^{-3}$. The residual error is $14 \mathrm{~kg} \mathrm{~m}^{-3}$ and the $95 \%$ confidence interval of our model is $3 \mathrm{~kg} \mathrm{~m}^{-3}$. To measure snow density and wetness continuously suitable sensors have been constructed. Their small size and high surface area to weight ratio minimizes their movement in the snowpack, except when they are exposed to intense solar radiation. Results show that changes in dry-snow density of less than $5 \mathrm{~kg} \mathrm{~m}^{-3}$ can be detected. Infiltration of even small amounts of water clearly shows up in the permittivity. At the surface of the snow pack, problems occur due to the formation of air pockets around the sensors during long-term measurements.
\end{abstract}

\section{INTRODUCTION}

Snow can be considered as a heterogeneous dielectric material consisting of ice, air and, in wet snow, of water. The density of snow and its liquid-water content are correlated to the dielectric properties. They are most often measured by capacitive methods. The methods developed for snow (Denoth and others, 1984; Denoth, 1989; Mätzler, 1996) can only be used for short-term measurements, because the required sensors are of a higher specific density than seasonal snow and absorb a substantial amount of solar radiation when they are located near the surface. Metallic cable time-domain reflectometry (TDR) has gained widespread use for measuring water content in soils and rocks (Topp and others, 1982; Herkelrath and others, 1991). A significant advantage compared to capacitive methods is the small sensitivity to variable conductivity. TDR sensors can be configured in different ways with little effort. This characteristic can be used to make sensors of different geometries, specifically adapted to the medium of interest. A disadvantage compared to capacitive measurements is the complex signal which is received by TDR. This signal requires a non-trivial interpretation before the permittivity can be calculated. The first application of TDR to the measurement of snow density and wetness was by Stein and Kane (1983). They only showed the signal but did not make calibrations. Schneebeli and Davis (1993) calibrated the dielectric constant and snow wetness for a limited number of values. Stein and others (1997) compared the dielectric constant measured by TDR to snow density and wetness. Lundberg (1996) concentrated on the measurement of snow wetness and fitted an empirical model to seasonal snow of a higher density $\left(350 \mathrm{~kg} \mathrm{~m}^{-3}\right)$.

Another possibility for measuring the dielectric snowcover properties over time is radar (Gubler and Hiller, 1984). Radar is a truly non-destructive technique. However, the layer-to-layer variation of the permittivity can only be determined by destructively measuring the snow density and height of each layer.

\section{THEORY}

The TDR method measures the return time of an electronic pulse transmitted through a finite-length cable or probe. The return time of the pulse is affected by both the length of the cable or probe (travel distance) and the permittivity of the insulator around the cable or probe (propagation velocity). Changes in impedance along the cable produce additional reflections that can be used to identify the location of the change. When the physical length of the probe is known, the permittivity of the insulator (snow) around the probe can be determined. The band of frequency where the permittivity is measured depends on the rise time of the pulse. Commercial TDR instruments are often in the range $10 \mathrm{MHz}$ to $1 \mathrm{GHz}$, with the central frequency around $200 \mathrm{MHz}$. This corresponds to a rise time of about $200 \mathrm{ps.}$

The apparent permittivity $\varepsilon_{\mathrm{a}}$ is defined as

$$
\varepsilon_{\mathrm{a}}=\varepsilon^{\prime} \frac{1+\sqrt{1+\tan ^{2} \delta}}{2}
$$

where $\varepsilon^{\prime}$ is the real part of the relative permittivity, $\varepsilon^{\prime \prime}$ is the imaginary part of the relative permittivity and the loss tan- 
gent $\tan \delta=\varepsilon^{\prime \prime} / \varepsilon^{\prime}$. The real part of the relative permittivity of ice is 3.15 and of air 1.00. The travel time of the electromagnetic pulse within the snow is determined by measuring the impedance mismatch at the beginning and end of the probe. The difference between these two locations gives an electromagnetic length $l_{\mathrm{el}}$. The relation between geometric probe length $l$, the apparent electromagnetic length $l_{\mathrm{el}}$ and the apparent permittivity $\varepsilon_{\mathrm{a}}$ is

$$
\varepsilon_{\mathrm{a}}=\frac{l_{\mathrm{el}}{ }^{2}}{(q l)^{2}}
$$

Due to impedance mismatches caused by impedance jumps (especially within the multiplexer), reflections occur which make calculation of the very small imaginary part of the permittivity $\varepsilon$ difficult if not impossible. For this work, we assume that for the frequency domain used by TDR the ratio $\varepsilon^{\prime \prime} / \varepsilon^{\prime} \ll 1$. The loss tangent would then be very small and the apparent permittivity corresponds to the real part of the permittivity.

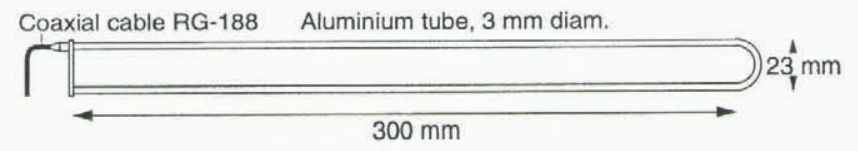

Fig. 1. Sketch of the construction snow probe. The snow probe is connected by a thin coaxial cable to the cable tester or the coaxial multiplexer.

\section{METHOD}

The experimental equipment consists of a cable tester (Tektronix 1502B), a notebook computer and the TDR probe. For continuous measurements in the snowpack, the automated measurements are done by interfacing a Campbell CR10 data logger and coaxial multiplexer. Two different types of TDR probe have been developed for measurements in snow. One is used for measurements in snow pits or in the laboratory (called the manual probe); the second one is used for long-term measurements within the snowpack (called the snow probe). The manual probe has a length of $28 \mathrm{~cm}$ and is two-pronged. Special attention has been given to an electromagnetically smooth transition from the coaxial cable to the two-pronged probe. The resulting signal is then as good as that from a three-pronged probe (cf. Zegelin and others, 1989). The ends of the two steel rods are sharp tips, such that even hard snow can be penetrated. A guide keeps the rods parallel when they are inserted and are removed before measurement. The snow probe is constructed from a thinwalled aluminum tube $(3 \mathrm{~mm}$ diameter, thickness of wall $0.3 \mathrm{~mm}$ ) (Fig. 1). The length of the probe is $300 \mathrm{~mm}$. Instead of the usual open circuit, the probe is short-circuited. This feature stabilizes the rods mechanically and changes the resulting signal only by sign (Fig. 2). The connectors are screwed SMA type and cables are thin $5 \mathrm{Ohm}$ coaxial (RG-188). The total weight of the sensor is about $10 \mathrm{~g}$. A semi-rigid aluminum frame with dimensions of $50 \mathrm{~cm} \times 50 \mathrm{~cm}$ has been constructed to position the probes flat on the snow surface. Three probes are fixed on the frame with $0.1 \mathrm{~mm}$ diameter nylon thread.

The electromagnetic length of the signal is calculated directly from the digitized signal. The digitized signal, consisting of 251 values and with a vertical resolution of 128 digits is first smoothed with a five-point moving average and i.org/10.3189/1998AoG26-1-69-72 Published online by Cambridge University Press converted to a real valued array (Fig. 2). This array is used to calculate the first derivative (centered difference). High values of the first derivative define an impedance mismatch. The algorithm checks for the first and second high values of the first derivative. These values are then used to locate the steady and rising part of the signal. Straight lines are fitted to the pieces and the intersections of the lines define the start of an impedance mismatch. The difference between these two values is used to calculate the electromagnetic length. This algorithm is similar to that of Heimovaara and Bouten (1990) but a simple linear regression is used instead of a weighted one, with no loss in locating the mismatch.

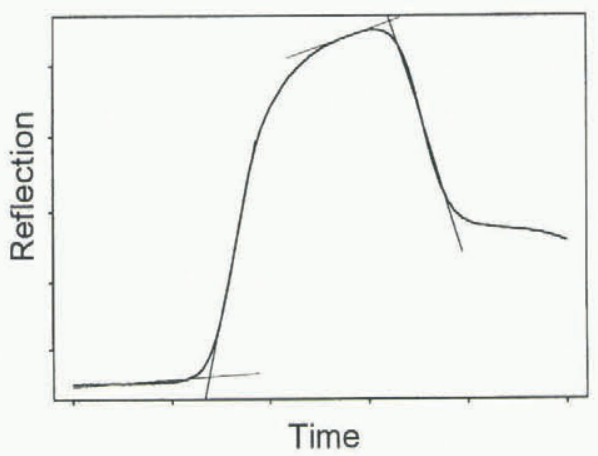

Fig. 2. Example of a digitized waveform from the snow probe. The end reflection is inverted compared to a normal probe ( see Fig. 3).

\section{LABORATORY MEASUREMENTS}

The calibration of snow density was done using different snow types and temperatures. The measurements at the Swiss Federal Institute for Snow and Avalanche Research (SFISAR) were made in the field, while those at the Centre d'Étude de la Neige (CEN) were done using sieved snow in the laboratory (Fig. 3). Both datasets show a similar amount of scatter. No influence of snow type or temperature could be observed. Grain-size has no effect on the measured permittivity. The apparent permittivity is highly correlated with gravimetrically determined snow density (correlation coefficient $r=0.988$ ). The formula

$$
\varepsilon_{\text {eff }}^{\prime}=0.99+0.00213 \rho_{\mathrm{s}}
$$

where $\rho_{\mathrm{s}}$ is the density of snow in $\mathrm{kg} \mathrm{m}^{-3}$, is the best fit to the

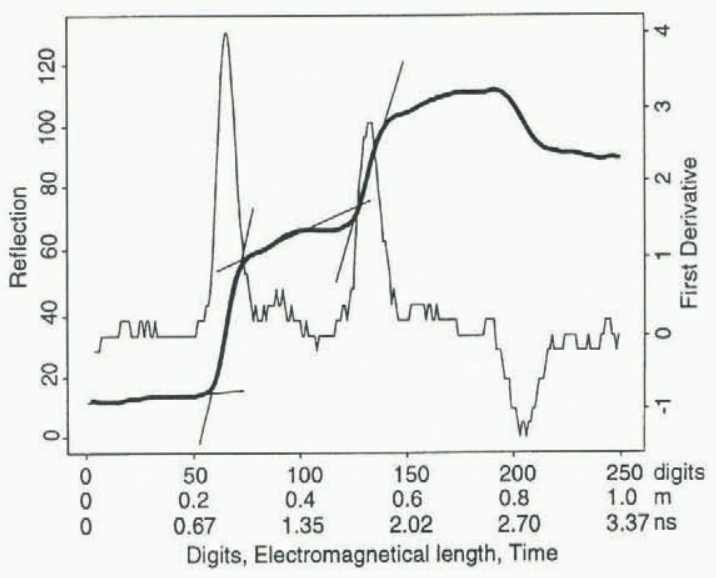

Fig. 3. Example of a digitized waveform. The thick line is the aquired wave. The absolute value of the first derivative diminishes with increasing travel time due to dispersion. 
data. This is very similar to the linear model of Tiuri and others (1984) where they proposed $\varepsilon_{\text {eff }}^{\prime}=1+0.0017 \rho_{\mathrm{s}}$ $+0.0007 \rho_{\mathrm{s}}{ }^{2}$. However, a systematic deviation between the measured values and the second-order polynomial model from Tiuri and others (1984) as well from Mätzler (1996), who found that $\varepsilon_{\text {eff }}^{\prime}=0.99+0.00159 \rho_{\mathrm{s}}+0.00186 \rho_{\mathrm{s}}{ }^{3}$, occurs (Fig. 4). The fit of Mätzler shows excellent agreement of the measurements with theory. The permittivities measured with TDR are higher. We suppose that this deviation is caused by the small compaction of the snow around the rods. The highest sensitivity of the electromagnetic field is directly around the rods (Knight and others, 1994) and the sign of the deviation is in the direction expected by such an effect. This hypothesis is supported by comparing the sensors used for the empirical fits of Tiuri and others (1984), Denoth (1989) and Mätzler (1996). The measurements by Tiuri and others were made using a two-pronged capacitive probe, those of Denoth using a plate and Mätzler's using a coaxial probe. The coaxial probe has the least compaction and the most homogeneous electromagnetic field. The measurements by Tiuri and others are between our relationship and that of Mätzler. The relationship of Denoth is between ours and Tiuri and others. Measurements using a coaxial probe correspond to a very high degree to those of Mätzler (personal communication from B. Lesaffre and F. Touvier, 1997). We conclude that the combined effects of compaction and distribution of the electromagnetic field caused by different sensors are important for measuring the relative permittivity in snow.

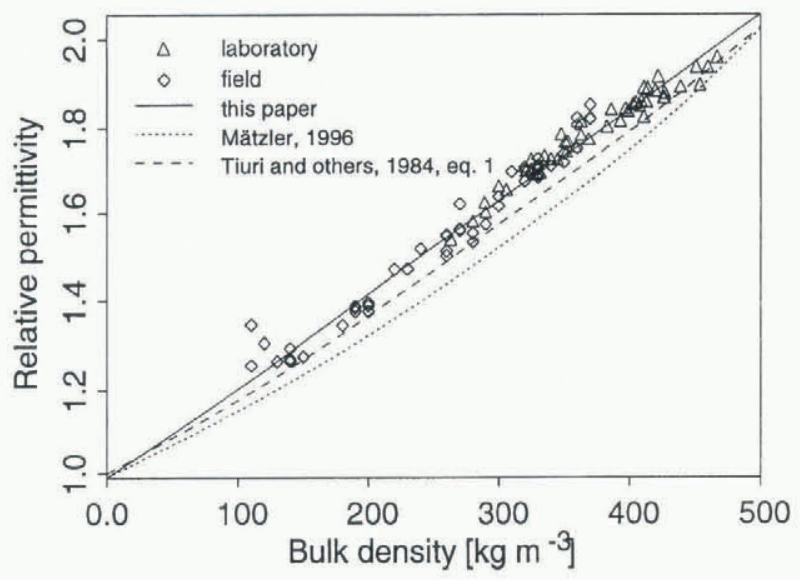

Fig. 4. Measured dry-snow density compared to the measured real part of the permittivity (symbols) and compared to empirical fits of snow density to permittivity.

The TDR measurements reported here are significantly better than those reported by Stein and others (1997). Their correlation coefficient $r$ is 0.78 for their best model and over a smaller range of densities $\left(150-400 \mathrm{~kg} \mathrm{~m}^{-3}\right)$ than measured in this study.

The wet-snow measurements in the laboratory do not show a good correlation to water content, especially when measured with different densities. This is caused by the difficulties in manufacturing sufficiently large and homogeneously wet-snow samples. Due to the rapid drainage of water from the snow, the samples taken for an independent determination of the water are already drier than the measurements taken with TDR at a high snow wetness. A more reliable method must therefore be sought. It was not possi- ble to improve the results of Schneebeli and Davis (1993) and Lundberg (1996) significantly.

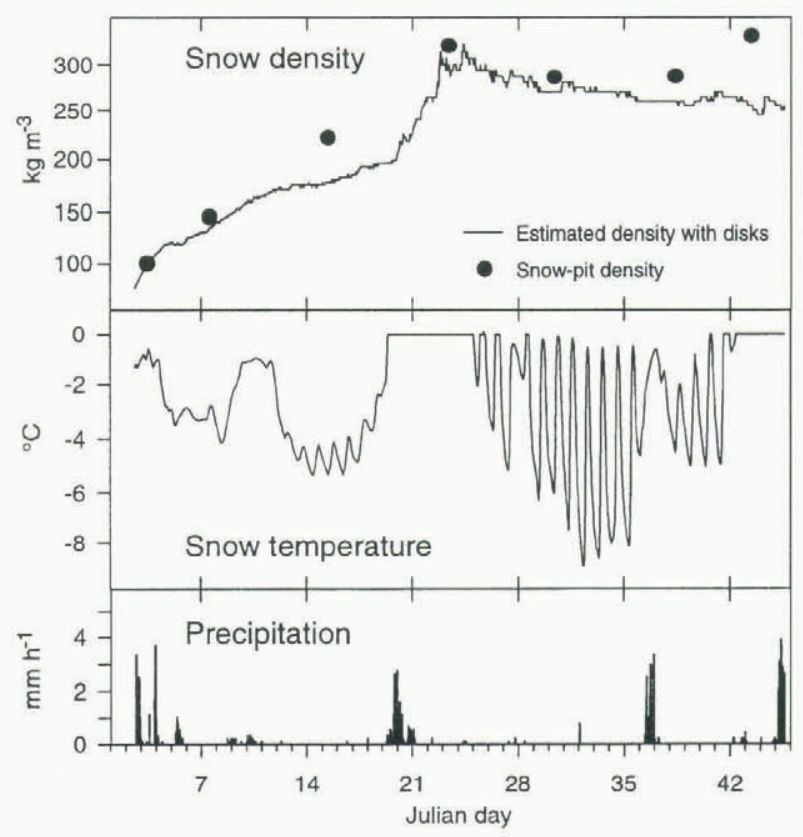

Fig. 5. Meteorological and snow data for the field measurements at Col de Porte. The snow density with disk is measured using a moving disk. Their heights are continously measured and the density can be calculated from the initial density and the settlement. The snow temperature is measured at the depths of the TDR snow probes.

\section{FIELD MEASUREMENTS}

The field measurements were done at Col de Porte in the French Alps (1325 ma.s.l.). The six probes were placed on the snow surface during a snowfall (Fig. 5). The probes were buried about $20 \mathrm{~cm}$ deep from day 2 to 22 and $5 \mathrm{~cm}$ deep from day 22 to 55 (Fig. 6). The calculated density (Equation (3)) of the snow measured by the probes is shown in Figure 7. The snow was dry until day 19. The increase in density caused by the settlement of the snow can be seen clearly. The calculated densities are lower than those measured in a nearby snow pit. Based on the few data, two explanations are possible. First, it may be the inverse effect observed during the laboratory calibration, because the snow probe

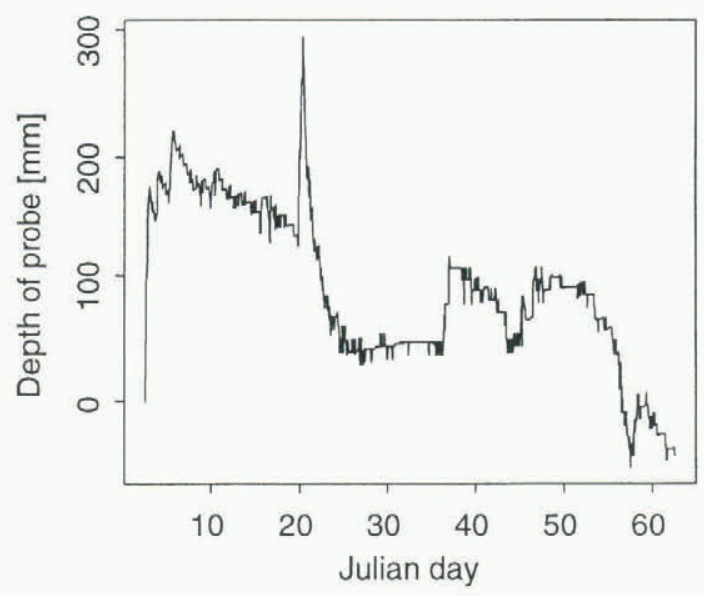

Fig. 6. Depth of the TDR snow probes below the surface. 
causes no compaction compared to the hand probe. Secondly, the snow-pit measurements are different from the density at the location of the TDR probes. The calculated density from disks moving in the snowpack is significantly lower on day 15 than the density measured in the snow pit (Fig. 5).

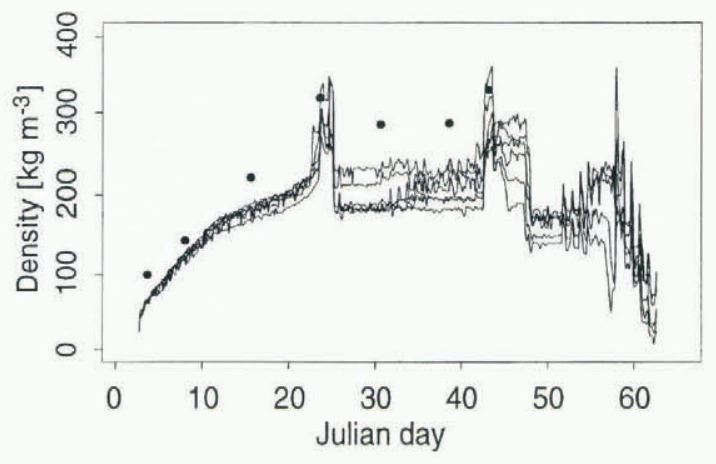

Fig. 7. Density calculated from the change in permittivity within the snow cover shown for the six probes within the same layer. The dots show the density measured in a nearby snow pit.

During the measurements, a high-frequency scatter is observed (Fig. 8). We suppose that this is caused by an instability in the electronics. These jumps could be removed using a median smoother to the time series.

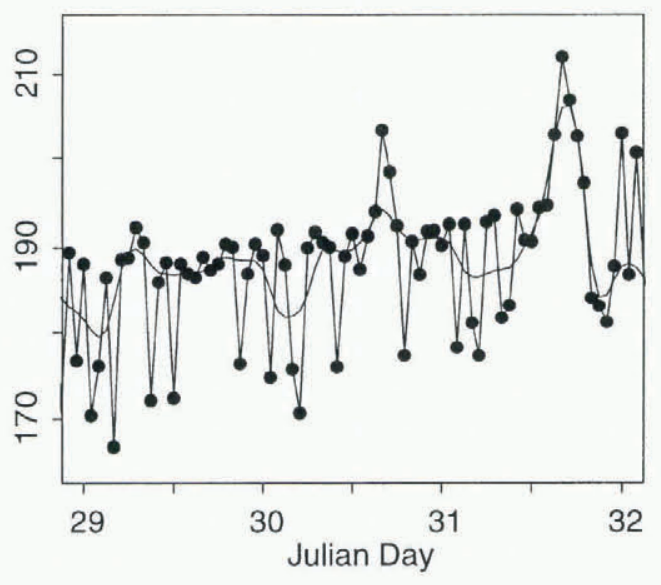

Fig. 8. Original signal of the TDR measurements (line with points) and median smoothed signal. The jumps are caused by the electronics used.

The sudden increase in density during and after day 23 is caused by liquid water (meltwater) and densification. The calculated density recedes to $200 \mathrm{~kg} \mathrm{~m}^{-3}$ following day 25 . This may be caused by the formation of an air pocket around the probes due to insulation, because from this time the snow probe was buried only by about $50 \mathrm{~mm}$ of snow. Although the snow temperature was near to $0^{\circ} \mathrm{C}$ during the day, the signal shows no meltwater infiltration with daily temperature fluctuations during days 24 to 42 . From days 42 to 48 , an increase in "density" can be recognized but this value cannot be quantitatively interpreted. Afterwards, the probes appeared at the surface of the snow.

\section{CONGLUSIONS}

TDR can be used to determine snow density with high precision and over an extended period, even when the sensor is only buried shallowly. It shows a very similar relationship between apparent permittivity and snow density as do other methods, which are based on frequency-domain methods. The lightweight sensors show promising potential for continuous measurement of the permittivity of snow in the field. In addition, the multiplexing possibilities will permit detailed analysis of infiltration patterns and variations in settlement. Calibration of the TDR system for liquid-water content has not yet been successful, because of the difficulties caused by manufacturing wet-snow samples. Infiltration events could be clearly detected with the continuously monitoring snow probe and the estimated water content was reasonable. Additional measurements are necessary, especially at greater depth, to evaluate the performance of the continuous measurements definitively.

\section{ACKNOWLEDGEMENTS}

We thank W. Caviezel for the skillful construction of the probes, R. Wetter for the electronics and C. Quadri for help with measurements.

\section{REFERENCES}

Denoth, A. 1989. Snow dielectric measurements. Adv. Space Res., 9 1), 233-243.

Denoth, A. and 6 others. 1984. A comparative study of instruments for measuring the liquid water content of snow. 7. Appl. Phys., 56 (7), 2154-2160.

Gubler, H. and M. Hiller. 1984. The use of microwave FMCW radar in snow and avalanche research. Cold Reg. Sci. Technol., 9 (2), 109-119.

Heimovaara, T. J. and W. Bouten. 1990. A computer-controlled 36-channel time domain reflectometry system for monitoring soil water contents. Water Resour. Res., 26(10), 2311-2316.

Herkelrath, W. N., S. P. Hamburg and F. Murphy. 1991. Automatic, realtime monitoring of soil moisture in a remote field area with time domain reflectometry. Water Resour. Res., 27(5), 857-864.

Knight, J. H., I. White and S. J. Zegelin. 1994. Sampling volume of TDR probes used for water content monitoring. In Time domain reflectometry in environmental, infrastructure, and mining applications. Minneapolis, MN, U.S. Department of Interior. Bureau of Mines, 93-104. (Special Publication SP 19-94.)

Lundberg, A. 1996. Laboratory calibration of TDR-probes for snow wetness measurements. Cold Reg. Sci. Technol., 25(3), 197-205.

Mätzler, C. 1996. Microwave permittivity of dry snow. IEEE Trans. Geosci. Remote Sensing, GE-34 (2), 573-581.

Schneebeli, M. and R. E. Davis. 1993. Time-domain-reflectometry as a method to measure snow wetness and density. In Armstrong, R., ed. ISSW'92. A Merging of Theory and Practice. International Snow Science Workshop, 4-8 October 1992, Breckenridge, Colorado. Proceedings. Denver, CO, Avalanche Information Center, 361-364.

Stein, J. and D. L. Kane. 1983. Monitoring the unfrozen water content of soil and snow using time domain reflectometry. Water Resour. Res., 19 (6), $1573-1584$.

Stein, J., G. Laberge and D. Lévesque. 1997. Monitoring the dry density and the liquid water content of snow using time domain reflectometry (TDR), Cold Reg. Sci. Technol., 25(2), 123-136.

Tiuri, M. T., A. H. Sihvola, E. G. Nyfors and M. T. Hallikainen. 1984. The complex dielectric constant of snow at microwave frequencies. IEEE 7 . Oceanic Eng., OE-9 (5), 377-382.

Topp, G. C., J. L. Davis and A. P. Annan. 1982. Electromagnetic determination of soil water content using TDR: II. Evaluation of installation and configuration of parallel transmission lines. Soil Sci. Soc. Am., J., 46, 678-684.

Zegelin, S. J., I. White and D. R. Jenkins. 1989. Improved field probes for soil water content and electrical conductivity measurement using time domain reflectometry. Water Resour. Res., 25(11), 2367-2376. 